\title{
NO TENGO TIEMPO. GEOGRAFÍAS DE LA PRECARIEDAD
}

\author{
I Have No Time. Geographies of Precariousness \\ Gabriela González Ortuño \\ Universidad Nacional Autónoma de México \\ gagortugno@gmail.com
}

Reseña de: MORUNO, Jorge (2018). No tengo tiempo. Geografías de la precariedad. Madrid: Akal.

Escribir una reseña en el "tiempo libre" es una tarea que muchas personas que se dedican al trabajo académico realizan: tomas un libro, lo lees y escribes algo acerca del impacto que el texto puede tener no sólo para el trabajo propio sino para el de otras obras o personas en sus quehaceres cotidianos. Escribir una reseña lleva su tiempo y, por lo general, se hace con una intención de difusión, rara vez es pagada. Para Jorge Moruno, quien analiza en su más reciente libro No tengo tiempo. Geografías de la precariedad, este tipo de labor sería parte de un movimiento del capitalismo contemporáneo que ha conseguido que el trabajo sea parte de cada momento de nuestra vida, en buena parte, gracias a la mediación tecnológica, la celurarización y la economía colaborativa, se trataría de "trabacaciones": "Hoy todo es tiempo humano disponible para el trabajo, del mismo modo que el trabajo necesita disponer de menos tiempo humano. Bajo la extensión de la competitividad, el tiempo se queda corto, por eso el crédito compra tiempo a futuro, especula y apuesta sobre la base de una promesa extendida en el tiempo" (Moruno, 2018, pág. 16).

Jorge Moruno hará uso de Marx Spinoza, Lordon, Althusser, Ranciere, Harvey, Stuart Hall y Foucault, entre otros, para hacer una amplia crítica al capitalismo actual que hace uso de recursos como lo emotivo, el tiempo y la mercantilización de las personas y sus espacios, antes privados, para generar valor y ganancia. En este ensayo dividido en seis partes, Moruno continúa el trabajo de análisis que comenzó en su libro anterior La fábrica del emprendedor. Trabajo y política en la empresa mundo (Akal, 2015) aunque esta vez Ilama la atención, no sólo sobre el uso del tiempo para la explotación y la mediación tecnológica, también en la manipulación ideológica que se construye a través del couching y la economía colaborativa.

Ante el panorama de inmediatez de comunicación que nos presentan las tecnologías actuales, Moruno habla de la forma en la que el tiempo se ha reconfigurado en la era del trabajo como vida, no como una cuestión que la atraviesa sino como algo que la constituye a través de promesas, por ejemplo, de una economía colaborativa en la que las personas usan el tiempo extra que tiene después de una jornada laboral formal o 
rentan sus bienes, autos, casas, bicicletas. Estas dinámicas y el crédito se erigen como los pilares del ideario de las nuevas formas laborales que, además, mantienen alejadas a las personas de la política que, por su parte, "se ha mercantilizado al mismo tiempo que el trabajo ha tomado la forma propia de la política" (Moruno, 2018, pág. 17).

La forma en la que se construye el tiempo social es una vía en la que se instauran las relaciones de dominación, por lo que el acceso y disfrute del tiempo está íntimamente relacionado con las formas de explotación existentes que mantienen a las personas alejadas de lo común, de lo político; debido a la repetición de los días, de los momentos, un ciclo que mantiene a las personas dentro de una idea de productividad que las conforman: "De este modo, comienza a tomar forma un tiempo nuevo, abstracto, que avanza a la par que se extienden las relaciones sociales capitalistas. En lugar de medir el tiempo partiendo de la duración de los hechos, sucede al revés y es el tiempo abstracto el que pasa a medir el tiempo de lo que se hace; la actividad. Es un tiempo uniforme, continuo, homogéneo e independiente de los acontecimientos." (Moruno, 2018, pág. 14)

Y no sólo eso, el tiempo contado a partir de la tecnologización de la vida y el trabajo, también hace mella de las emociones. ¿Quién no busca relajarse revisando sus redes sociales o buscando alguna serie o documental online? El acceso a las relaciones virtuales ha conseguido abrir nuevos nichos de mercado: aplicaciones para conseguir pareja, para buscar acompañantes, para solicitar un abrazo o un paseo acompañados. La fragmentación de la vida comunitaria por los tiempos laborales ha terminado por mercantilizar la soledad: "Instagram, al mismo tiempo, hace las veces de panóptico integrado, no porque vigile sino porque dinamiza el acceso a la relación y, por tanto, genera una mediación desde la cual se interiorizan relaciones de poder con un fuerte componente de adhesión libidinal" (Moruno, 2018, pág. 27).

Para nuestro autor, esto hace parte del avance de una desidentificación como trabajadores, la identidad política a la que apelaba la izquierda con antelación, la lucha obrera y trabajadora que, sin embargo, se ha desdibujado a través de las formas laborales actuales, mediadas por la tecnología en las que se busca ganar por todo medio y todo el tiempo, de tal forma que nos encontramos con servicio de renta del auto o casa propia para el uso de otros o rentando nuestro tiempo libre. El tiempo para dedicar a la política se diluye; las identidades políticas devienen superficiales, los obreros ya no se reconocen como tales sino como prestadores de servicios o consumidores.

En la economía solidaria, el capitalismo ha encontrado una forma de mercantilizar lo que antes era impensable: el tiempo libre, ahora se puede usar rentando el auto y el servicio de manejo; la vivienda y los servicios de mantenimiento; existen becarios que trabajan sin paga a cambio de una recomendación. En este sentido:

Si Marx explicaba que la fuerza de trabajo «da crédito al capitalista» adelantando su valor de uso, hoy, a través de prácticas, becas y horas extra sin remunerar se regala tiempo valioso sin que nadie te lo compre y pague por ello, a modo de muestra gratuita: las formas no remuneradas de trabajo, vendidas como «oportunidad» y «privilegio» en forma de prácticas y becarios, 
son la adaptación neoliberal del trabajo voluntario. La vida se convierte en un yacimiento de oportunidades de negocio. Todo lo que no era un servicio, ahora sí lo es. Para formar parte del circuito de oportunidades de eso que es el ser-negocio, basta con ser-ente. Todo aquello que pueda ser considerado cosa, es espacio de capitalización; todo lo que es, es susceptible de ser cosa; es decir, mercancía. (Moruno, 2018, pág. 43)

Esto implica que el capitalismo actual es capaz de arrebatarnos la capacidad de dar. El don no existe más en un mundo en el que lo que antes se ofrecía como señal de amistad u hospitalidad se cobra a través de una aplicación. Las grandes empresas que desarrollan o compran aplicaciones ganan con la función de la mediación, proporcionan un espacio para negociar y eso es suficiente para obtener valor.

Es importante decir que no todas las personas van a ser capaces de pagar por lo que otras ofertan, "Esta lógica entiende la cooperación social o el interés únicamente enfocado al beneficio económico como dominación abstracta; sin embargo, si todos los ámbitos de nuestra vida se someten a la oferta y la demanda, el acceso se restringe a quien puede pagar un precio que mucha gente no podría pagar." (Moruno, 2018, pág. 79), por lo que estos servicios continúan con la diferencia de clases, sino la aumentan porque el goce de tiempo libre dependerá del precio que se pueda pagar. Es importante aclarar que la visión del autor se circunscribe a un análisis eurocentrado, al que otras visiones de mundo no corresponden necesariamente. Por ejemplo, aunque en México el uso de aplicaciones ha aumentado, sólo 4 de 10 personas tienen acceso a Internet. ${ }^{1}$ Esto es sólo para ponderar un análisis que es necesario frente a la oleada informática y el constante bombardeo de novedades tecnológicas.

Moruno da como una clave para salir de este panorama al ecofeminismo, al que piensa más que en un horizonte, en dos formas de pensamiento y acción desde las cuáles deben moverse nuestras sociedades, de forma "porosa", cuestiones que se adapten para construir relaciones distintas y radicalmente opuestas a las que nos enfrentamos. Sin embargo, Moruno no ahonda en este punto que podría mostrar un horizonte mucho menos distópico e, incluso, menos eurocentrado. En el contexto de avance voraz del capitalismo, las respuestas situadas, ligadas a formas distintas de concebir la vida ligadas al ecofeminismo y otras luchas como las de defensa del territorio afro o indígena desde Latinoamérica resisten, podría complementar su argumentación.

Hay una línea muy cercana entre Alberto Santamarina (Akal, 2018) o Frederic Lordon (Tinta Limón, 2015) en cuanto al abordaje de las nuevas formas de explotación laboral, el uso del tiempo, de la tecnología y la mercantilización de los afectos desde una perspectiva marxista. En este libro, es posible discernir de manera crítica las supuestas oportunidades que otorga el acceso a la tecnología que se presenta como una herramienta de explotación acabada en tanto aprovecha el tiempo y el afecto de cada persona para

${ }^{1}$ Esto según datos de la Encuesta Nacional sobre Disponibilidad y Uso de Tecnologías de la Información en los Hogares 2017 (ENDUTIH). 
expandir sus nichos de mercados en la idea de proveer servicios. Esto, es un primer paso para pensar en la reconfiguración de resistencias y en la forma de re pensar lo político.

\section{BIBLIOGRAFÍA}

Lordon, F. (2015). Capitalismo, deseo y servidumbre. Marx y Spinosa. Buenos Aires: Tinta Limón.

Moruno, J. (2015). La fábrica del emprendedor. trabajo y política en la empresa-mundo. Madrid: Akal.

Moruno, J. (2018). No tengo tiempo. Geografías de la precarierdad. Madrid: Akal.

Santamarina, A. (2018). En los límites de lo posible. Política cultura y capitalismo afectivo. Madrid: Akal. 